\title{
Grand challenges in vascular physiology
}

\author{
Gerald A. Meininger* \\ Dalton Cardiovascular Research Center and Department of Medical Pharmacology and Physiology, University of Missouri, Columbia, MO, USA \\ ${ }^{*}$ Correspondence: meiningerg@missouri.edu
}

Cardiovascular disease continues to reign as a leading cause of premature death (National Center for Health Statistics, 2007; Lloyd-Jones et al., 2010) having a major impact on global society from both a social and economic perspective. The costs of cardiovascular disease are projected to exceed $\$ 315$ billion dollars annually in the US alone in 2010 (Heron, 2007; Mensah and Brown, 2007). Furthermore, there will be a rapid increase in the prevalence of vascular disease due to increasing diseases of western society (insulin resistance, diabetes, etc.) and westernization of developing countries. The importance of altered vascular function and its contributions to both etiology and progression of cardiovascular disease has been clearly established. Yet, many of the underlying mechanisms that could provide definitive clues to unraveling the disease mechanisms leading to improved therapeutic targeting, diagnosis and ultimately cures are shrouded by a lack of understanding. We continue to need a more detailed and comprehensive understanding of the events occurring within the blood vessel wall and its interactions with blood components. As the functions of the intact vessel wall are being revealed, we must connect and integrate the information occurring across different organizational levels to develop a complete understanding of vascular phenomena. Devising new approaches and processes for integration of this complex information is one of the foremost challenges in this rapidly paced era of science. Major breakthroughs are needed in understanding the mechanisms underlying vascular development, growth, structure, and mechanical properties including the vascular networks they comprise. For advances in tissue engineering there is a pressing need for understanding how blood vessels form and how to create functional blood vessels and how they organize into functional vascular networks. Achieving this goal will be a major advance for the repair of existing vessels and development of tissue constructs for the healing and replacement of damaged tissue. Of course, there are many other challenges to overcome and a multitude of factors at work shaping the field (Granger, 1998).

The history and chronicle of scientific progress in vascular physiology is rich with significant advances that have repeatedly shaped our current concepts and theoretical paradigms (Warren, 1975; Chevalier, 1976; Fishman and Richards, 1982; Granger, 1998) and continue to do so. These advances come in the form of new factual information and concepts as well as technology. As the last century ended, it was clear that multidisciplinary, integrated approaches to understanding vascular physiology were becoming the increasingly accepted approach to refining our knowledge and understanding. These same trends have also been redefining the organization of our academic and scientific institutions on a global scale. Internationally a majority of scientific institutes and centers pursue their research agendas with multidisciplinary strategies that are focused on strategic areas or research thrusts as opposed to unidisciplinary academic units. Hopefully, this evolutionary process will facilitate further interdisciplinary co-operation and interaction at even deeper levels resulting in a greater understanding of how systems work together.

Acknowledging the role of technology in the field is required since often testing bold new ideas, representing the most advanced contemporary scientific thinking is limited by the lack of appropriate technology. This, like any barrier, restricts advancement. However, vascular scientists are today very fortunate to live in a world where current technology and the pace of technological developments permit us to breakthrough these barriers and realize these ideas with increasing alacrity. Advancing technology brings with it new observations to feed our imagination with possibilities fostering another round of novel ideas for future exploration. Thus, an important challenge is to continue to develop research technology to address new questions rather than rely solely on existing approaches. Technology can make what seemed the impossible now possible and shorten the journey between a "good" idea and the successful experiment. This being said the field is also challenged with not losing "tried and true" in vivo approaches that cannot be allowed to disappear but must continue to be refined and developed.

From the scale of molecules to the whole organism, scientific approaches to investigating vascular physiology continue to take many forms in the modern laboratory: from integrative to reductionist, from hypothesis driven to discovery driven and from deductive to inductive. Appreciating these differences in scientific inquiry is challenging and can in part be understood by recognizing the multidisciplinary backgrounds of vascular scientists. For modern students of vascular physiology, never before has it been more important to understand the collective incorporation of biological and engineering principles and application of physics and chemistry to understanding the blood vessel wall and its interactions with blood. As it is not practical to become expertly versed in all disciplines, new paradigms for research and training are incorporating approaches that take advantage of these multiple approaches (Humphrey et al., 2005). Toward this goal, the interdisciplinary research team provides a degree of synergy that enhances creativity, productivity, and translation.

In summary, vascular physiology has numerous challenges facing it for the future. To name a few, these include:

a. Refining and developing analytical approaches to integrate existing knowledge such as modeling and bioinformatic strategies

b. Adding or accumulating new knowledge - using and developing new technology

c. Increasing need for multidisciplinary approaches that focus diverse expertise on vascular physiology

d. Improving models for the study of vascular disease - implement translation 
Frontiers in Vascular Physiology is a new and electronic forum for dissemination of information that will benefit the global community of vascular scientists. The goal is to provide a publishing environment that through rapid access promotes an increased understanding of vascular physiology and the pathological processes that result in cardiovascular disease.

\section{REFERENCES}

Chevalier, P. (Ed.). (1976). Benchmark Papers in Human Physiology: The Heart, and Circulation, Vol. 8. Stroudsburg, PA: Dowden, Hutchinson and Ross.

Fishman, A. P., and Richards, D. W. (Eds). (1982). Circulation of the Blood: Men and Ideas. Bethesda, MD: America Physiology Society.

Granger, H. J. (1998). Cardiovascular physiology in the twentieth century: great strides and missed opportunities. Am. J. Physiol. 275; Heart Circ. Physiol. 44, H1925-H1936.
Heron, M. P. (2007). Deaths: leading causes for 2004 [PDF-3.2M]. National Vital Statistics Reports. 56, 5. Hyattsville, MD: National Center for Health Statistics.

Humphrey, J. D., Cot'e, G. L., Walton, J. R., Meininger, G. A., and Laine, G. A. (2005). A new paradigm for graduate research and training in the biomedical sciences. Adv. Physiol. Educ. 29, 98-102.

Lloyd-Jones, D., Adams, R. J., Brown, T. M., Carnethon, M., Dai, S., De Simone, G., Ferguson, T. B., Ford, E., Furie, K., Gillespie, C., Go, A., Greenlund, K., Haase, N., Hailpern, S., Ho, P. M., Howard, V., Kissela, B., Kittner, S., Lackland, D., Lisabeth, L., Marelli, A., McDermott, M. M., Meigs, J., Mozaffarian, D., Mussolino, M., Nichol, G., Roger, V. L., Rosamond, W., Sacco, R., Sorlie, P., Roger, V. L., Thom, T., Wasserthiel-Smoller, S., Wong, N. D., and WylieRosett, J. (2010). Heart disease and stroke statistics - Update. A report from the American Heart Association Statistics Committee and Stroke Statistics Subcommittee. Circulation 121, e1-e170. Mensah, G., and Brown, D. (2007). An overview of cardiovascular disease burden in the United States. Health Aff. 26, 38-48.
National Center for Health Statistics. (2007). Fast Stats, Heart Disease. Hyattsville, MD: National Center for Health Statistics, 2007. Available at: http://www.cdc. gov/nchs/fastats/heart.htm. Accessed September 20, 2007.

Warren, J. V. (Ed.). (1975). Benchmark Papers in Human Physiology: Cardiovascular Physiology, Vol. 4. Stroudsburg, PA: Dowden, Hutchinson, and Ross.

Received: 08 June 2010; accepted: 09 June 2010; published online: 28 June 2010.

Citation: Meininger GA (2010) Grand challenges in vascular physiology. Front. Physio. 1:18. doi: 10.3389/ fphys.2010.00018

This article was submitted to Frontiers in Vascular Physiology, a specialty of Frontiers in Physiology.

Copyright $\odot 2010$ Meininger. This is an open-access article subject to an exclusive license agreement between the authors and the Frontiers Research Foundation, which permits unrestricted use, distribution, and reproduction in any medium, provided the original authors and source are credited. 